\title{
Physiological and Growth Response of Sweet Corn Hybrids to Aluminum-Induced Stress
}

\author{
Jing-sheng Fan ${ }^{1, \uparrow}$, Yun-feng $\mathrm{Li}^{1, \uparrow}$, Fu-gui Xie ${ }^{1}$, Zhao-wen $\mathrm{Mo}^{1}$, Xia-ming $\mathrm{Wu}^{1}$, Qia $\mathrm{Lin}^{1}$, Wei Zhu ${ }^{1}$, \\ Yan-hong Chen ${ }^{2}$, Yu Liu ${ }^{1}$, Jun Huang ${ }^{1}$, Qing-you Gong ${ }^{2} \&$ Fa-qiang Feng ${ }^{1}$ \\ ${ }^{1}$ The Key Laboratory of Plant Molecular Breeding of Guangdong Province, College of Agriculture, South China \\ Agricultural University, Guangzhou, Guangdong, China \\ ${ }^{2}$ Zhuhai Modern Agricultural Development Center, Zhuhai, Guangdong, China \\ Correspondence: Fa-qiang Feng, The Key Laboratory of Plant Molecular Breeding of Guangdong Province, \\ College of Agriculture, South China Agricultural University, Guangzhou 510642, Guangdong, China. Tel: \\ 00-86-020-85288331. E-mail: fengfq@scau.edu.cn
}

Received: February 6, 2020

Accepted: June 21, $2020 \quad$ Online Published: July 15, 2020

doi:10.5539/jas.v12n8p71

URL: https://doi.org/10.5539/jas.v12n8p71

${ }^{\dagger}$ These authors contributed equally to this article.

\begin{abstract}
Aluminum (Al) stress has strong negative effects on growth, development and yield formation in crops. However, few studies focused on aluminum stress in sweet corn seedlings. In the present study, 18 sweet corn varieties were used to analyze the morphological and physiological changes of sweet corn seedlings in response to $\mathrm{Al}$-induced stress. Results have shown that treatment by $\mathrm{AlCl}_{3}$, significantly affected root elongation, chlorophyll content, plant height, fresh weight, superoxide dismutase (SOD) activity, peroxidase (POD) activity, catalase (CAT) activity and $\mathrm{Al}$ content in root tips in sweet corn, according to the significant interaction by variety $\times$ $\mathrm{AlCl}_{3}$ treatment except for CAT. Al-induced stress inhibited root length in all sweet corn varieties, and it resulted in a decrease in chlorophyll content, plant height, fresh weight, and SOD activity in most of the sweet corn varieties. The treatment by $\mathrm{AlCl}_{3}$ increased in POD activity except for GLT31; however, the intensity of these effects varied among varieties. In addition, the correlation between morphological and physiological characteristics showed that $\mathrm{Al}$ content in root tips was negatively correlated with relative root growth (RRG) and chlorophyll content at a significant level of 0.01 , and it was negatively correlated with CAT activity at the significant level of 0.05 . There were significant positive correlations between plant height and fresh weight at a significant level of 0.01 , and chlorophyll content was positively correlated with RRG and CAT at the significant level of 0.05 . The principal component analysis showed that plant height, RRG, SOD activity, fresh weight, Al content of root tips and fresh weight were the main morphological and physiological characteristics in sweet corn seedlings affected by $\mathrm{AlCl}_{3}$ treatment. In addition, we found that HWT2, HWT1 and HZ388 were the high-tolerant varieties to $\mathrm{Al}$ treatment.
\end{abstract}

Keywords: sweet corn, seedlings, aluminum stress, morphological and physiological characteristics

\section{Introduction}

Human industrial and agricultural production activities have accelerated soil acidification, and it has been estimated that approximately $50 \%$ of the world's arable land is acidic (Ryan \& Delhaize, 2010; Kochian, 1995). Furthermore, $22.7 \%$ of the total land area in China consists of acid soils (Huang et al., 2001). Aluminum (Al) is the most abundant metal element in the earth's crust, but its toxicity to higher plants depends on soil $\mathrm{pH}$ value (Bojórquez-Quintal et al., 2017). Thus, soil acidification can activate the transformation of Al minerals, promoting the change of bound $\mathrm{Al}$ to the ionic state. These forms of $\mathrm{Al}$ are available for higher plants in soil and exhibit phytotoxicity (Ulrich \& Panbrath, 1983; MacDonald \& Martin, 1998).

Al toxicity in acidic soil severely restricts crop yield and quality (Foy \& Chaney, 1978; Matsumoto, 2000). Previous studies have shown that the root elongation is inhibited and the growth of above-ground parts is hindered under the Al toxicity stress, resulting in decreased biomass of the whole plant (Rengel, 1992; Kollmeier et al., 2000). Al stress can also reduce the chlorophyll content and inhibit the activities of enzymes involved in 
photosynthesis, leading to a decrease of photosynthetic rate, and serious plant growth obstructions (Zhao et al., 2008). Al content, $\mathrm{H}_{2} \mathrm{O}_{2}$ content, MDA content, and POD activity in the roots increased in $\mathrm{B} 73$ and 178 maize lines and these physiological indexes reached the maximum after Al treatment for $24 \mathrm{~h}$ (Zhou et al., 2014). Reactive oxygen species (ROS) burst and ROS-mediated plasma membrane oxidative damage have been considered to be one of the main reasons for plant growth inhibition induced by Al stress (Yam et al., 2002). Under normal conditions, ROS production and scavenging are in a steady-state, equilibrium in plant, which is not harmful to plant (Dietz et al., 2016). However, ROS burst in response to Al stress causes serious damage to the structure and integrity of plasma membrane in plant, resulting in oxidative damage, and ultimately inhibiting plant absorption of nutrients and water (Huang et al., 2014). Superoxide dismutase (SOD), peroxidase (POD) and catalase (CAT) are important antioxidative enzymes in plant, and they protect cells from oxidative damage by scavenging ROS through synergistic action (Yang et al., 2010). So these antioxidative enzymes could be indicators of aluminum toxicity resistance.

Sweet corn (Zea mays L. sacharata Sturt) is a special type of corn with a recessive mutation in the endosperm starch synthesis gene; and China is the leading country in sweet corn production and consumption in the world. More specifically, South China is the main producing area, accounting for more than $50 \%$ of the total sweet corn production in the country. However, the soil in South China is a typical acidic soil such as red soil, lateritic red soil, and lateritic red soil. Al toxicity in such soil seriously restricts the development of sweet corn production. Moreover, previous research has shown that corn is more sensitive to Al toxicity than wheat and rice (Boscolo et al., 2003). For the reasons indicated, in this study, 18 sweet corn varieties were cultured in the nutrient solution, and the characteristics of morphological and physiological indexes under Al stress were studied, in order to reveal the differences and analyze the physiological characteristics of sweet corn in response to Al stress.

\section{Method}

\subsection{Experimental Materials}

Eighteen sweet corn varieties widely planted in South China were used in this study, including Guangtian No.8 (GT8), Jinbaitian No.10 (JBT10), Huanong No.168 (HN168), Huajintian No.1 (HJT1), Huanong No.3 (HN3), Huaweitian No.2 (HWT2), Meizhentian No.1 (MZT1), Huaweitian No.1 (HWT1), Litian No.8 (LT8), Guangliangtian No.31 (GLT31), Zhongtian No.8 (ZT8), Zhuyutian No.1 (ZYT1), Jinguangxi (JGX), Yuetian No.30 (YT30), Huazhen No.388 (HZ388), Huangcai No.11 (HC11), Guangtian No.18 (GT18), and Hantian No.309 (HT309).

\subsection{Experiment Design}

Eighteen sweet corn varieties, with 30 equally sized seeds in each variety, were selected and rinsed with $2 \%$ sodium hypochlorite $(\mathrm{NaClO})$ for $3 \mathrm{~min}$. After that, seeds were washed with distilled water and placed in a germination box covered with wet filter paper. The germination process was stimulated in a constant-temperature incubator at $25^{\circ} \mathrm{C}$. After reaching a size of $1-1.5 \mathrm{~cm}$, seedlings were transferred to a petri dish with filter paper, and grown in equal volumes of Hoagland's nutrient solution $(\mathrm{pH}=6)$. At the three-leaf stage, 16 seedlings with healthy and consistent growth were selected for each variety. Eight seedlings of 16 seedlings from each variety were transplanted into a water culture bucket, containing $2 \mathrm{~L}$ nutrient solution, and fixed to sponges. All 16 seedlings were divided into two groups. One group was treated with $0.0 \mathrm{mmol} \mathrm{L}^{-1} \mathrm{AlCl}_{3}(\mathrm{CK})$ and the other group was treated with $0.4 \mathrm{mmol} \mathrm{L}^{-1} \mathrm{AlCl}_{3}$ (Al treatment). Ventilation was performed daily for $10 \mathrm{~min}$, and the nutrient solution was changed every 3 days. After 7 days of culture, the morphological and physiological indexes of different sweet corn varieties were measured. The experiment was repeated three times.

\subsection{Determination of Relative Root Growth}

The sweet corn seedlings were treated at the three-leaf stage of growth with $0 \mathrm{mmol} \mathrm{L}^{-1} \mathrm{AlCl}_{3}(\mathrm{CK})$ and 0.4 mmol L${ }^{-1} \mathrm{AlCl}_{3}$ (Al treatment). The initial length of the primary roots was measured for 8 seedlings in each treatment. After 24 hours of Al-toxicity treatment, the primary root length was measured again. The root tip elongated length (RTEL) was calculated by the root tip length after 24 hours subtracted from the initial root length. The relative root growth (RRG) of sweet corn seedling was expressed as the percentage of root growth after $\mathrm{Al}$ treatment in comparison to $\mathrm{CK}$.

\subsection{Determination of Al Content in Root Tips}

Eight root tips, 1-2 cm long, of each variety, were treated with $\mathrm{Al}^{3+}$ for 7 days; subsequently, $\mathrm{Al}$ was extracted by $8.0 \mathrm{ml}$ of $2.0 \mathrm{~mol} \mathrm{~L}^{-1} \mathrm{HCl}$ and left for 48 hours. Then $5.0 \mathrm{ml}$ of supernatant was obtained by centrifugal filtration and the $\mathrm{Al}$ content in root tips was quantified using inductively coupled plasma spectrometer (Inductively Coupled Plas) (Piñeros \& Kochian, 2001). 


\subsection{Determination of Plant Height, Fresh Weight, and Chlorophyll Content of Sweet Corn Seedlings}

Plant height was determined the distance from the bottom to the tip of the plant, after the endosperm removal from the seedling. The water on the leaf was dried with absorbent paper, and the fresh weight was measured with a 1/10000 balance. The relative leaf chlorophyll concentration measurement, expressed in SPAD values, was performed on the upper leaf using chlorophyll SPAD meter (SPAD-502Plus).

\subsection{Determination of Antioxidant Enzyme Activities}

After culturing in nutrient solution for 7 days, the leaves of the $\mathrm{Al}^{3+}$ treatment group were accurately weighed and ground into powder in liquid nitrogen; subsequently, $0.1 \mathrm{ml}$ of phosphate buffer was added according to the specific ratio (weight $(\mathrm{g})$ : volume $(\mathrm{ml})=1: 5$ ) in order to obtain the homogenate. The homogenate was centrifuged for 10 minutes at $8000 \mathrm{rpm}$ at $4{ }^{\circ} \mathrm{C}$, and the supernatant was used for further examination. The activities of SOD, POD, and CAT enzymes were determined according to the instructions of the corresponding kit (Nanjing Jiancheng Bioengineering Research Institute, Nanjing, China). SOD, POD, and CAT were combined with the capture antibody, and then chromogenic reaction generated by the substrate TMB $\left(3^{\prime}, 3^{\prime}, 5^{\prime}, 5^{\prime}\right.$-tetramethylbenzidine). TMB was converted to blue under the catalysis of these antioxidant enzymes, and finally to yellow under the action of acid. The sample concentration of SOD, POD, and CAT were calculated by measuring absorbance at $450 \mathrm{~nm}$.

\subsection{Data Analysis}

Microsoft Excel 2013, IBM SPSS Statistix 19, and GraphPad Prism 7 were used for data input, statistical analysis, and drawing. Two-way ANOVA was performed to analyze the effect of variety, Al treatment and the interaction by variety $\times \mathrm{Al}$ treatment. The multiple comparisons of different varieties were performed by Duncan's test and the comparison between CK and Al treatment in each variety was carried out by LSD's test.

\section{Results}

\subsection{Effects of Al Stress on Morphological and Physiological Characteristics of Different Sweet Corn Varieties and Analysis of Variance}

\subsubsection{Effect on the Root Tip}

The $\mathrm{F}$ values of varieties, treatment by $\mathrm{AlCl}_{3}$ and their interaction were analyzed by two-way ANOVA (Table 1). The variance of varieties was extremely significant in the six morphological and physiological traits except for the relative chlorophyll content, the variance of the treatment by $\mathrm{AlCl}_{3}$ was extremely significant in all seven morphological and physiological traits by F-test. The extremely significant interaction by variety $\times$ treatment by $\mathrm{AlCl}_{3}$ treatment was observed in the six morphological and physiological traits except for CAT activity.

Table 1 . The $\mathrm{F}$ values of varieties, treatment by $\mathrm{AlCl}_{3}$ and their interaction in these morphological and physiological traits using two-way ANOVA

\begin{tabular}{|c|c|c|c|c|c|c|c|}
\hline & Root length & $\begin{array}{l}\text { Relative chlorophyll } \\
\text { content }\end{array}$ & Plant height & $\begin{array}{l}\text { Seedling } \\
\text { fresh weight }\end{array}$ & SOD activity & POD activity & CAT activity \\
\hline Variety & $29.53 * *$ & 1.59 & $14.41 * *$ & $19.95 * *$ & $816.51^{* *}$ & $912.48 * *$ & $373.49 * *$ \\
\hline Al treatment & $9.08 * *$ & $2.67 * *$ & $6.88 * *$ & $14.70 * *$ & $985.51 * *$ & $953.84 * *$ & $543.37 * *$ \\
\hline Interaction & $41.12 * *$ & $12.74 * *$ & $22.64 * *$ & $7.60 *$ & $17.06 * *$ & $23.95 * *$ & 0.80 \\
\hline
\end{tabular}

Note. ${ }^{*}$ and ${ }^{* *}$ indicate significant difference at the level of 0.05 and 0.01 .

Multiple comparisons of the mean root tip elongated length were carried out under the condition of $\mathrm{CK}$ and $\mathrm{Al}$ treatment (Table 2). Our results showed that Al treatment inhibited the root tip elongation significantly in sweet corn seedlings. The maximum root tip elongated length was variety YT30 under these two conditions. In most of the 18 sweet corn varieties showed the same change trend under these two conditions. The relative root growth of 18 sweet corn varieties ranged from $32.86 \%-83.02 \%$ after $24 \mathrm{~h}$ of treatment with $0.4 \mathrm{mmol} \mathrm{L}^{-1} \mathrm{AlCl}_{3}$. The mean of $\mathrm{Al}$ content in root tips was $1.88 \mu \mathrm{g} \mathrm{ml}^{-1}$ with a range of 0.99-3.67 $\mu \mathrm{g} \mathrm{ml}^{-1}$. In varieties HJT1, HWT2, HWT1, GLT31, ZYT1, LT8, HZ388, and GT18, the inhibition of root length was low, the relative root growth was high (RRG > 0.6), and the range of Al content in root tip was $0.99 \sim 1.70 \mu \mathrm{g} \mathrm{ml}^{-1}$. In varieties JBT10, MZT1, ZT8, HC11 and HT309, the root tip elongation was greatly inhibited, the relative root growth was low $(R R G<0.5)$, and the range of $\mathrm{Al}$ content of root tips was 1.81-3.66 $\mathrm{g} \mathrm{ml}^{-1}$. The difference of relative root growth and Al content of root tips among 18 sweet corn varieties was significant at the level of 0.05 and 0.01 , respectively by F-test. 
Table 2. Effect of Al treatment on the relative root growth and Al content in root tips

\begin{tabular}{|c|c|c|c|c|}
\hline Sweet corn lines & $\mathrm{CK}$ & Al treatment & Relative root growth & Al content in root tips \\
\hline & \multicolumn{2}{|c|}{-------------- RTEL (cm) ------------- } & ---------- \% ---------- & ------- $\mu \mathrm{g} \cdot \mathrm{ml}^{-1}$ \\
\hline GT8 & $0.50 \pm 0.06 \mathrm{cdef}$ & $0.25 \pm 0.09 \mathrm{bcd}$ & 55.56 & 1.95 \\
\hline JBT10 & $0.55 \pm 0.03$ cde & $0.25 \pm 0.03 \mathrm{bcd}$ & 45.15 & 1.81 \\
\hline HN168 & $0.80 \pm 0.06 \mathrm{~b}$ & $0.40 \pm 0.06 \mathrm{abc}$ & 51.59 & 1.95 \\
\hline HJT1 & $0.60 \pm 0.06 \mathrm{bcd}$ & $0.50 \pm 0.06 \mathrm{ab}$ & 83.02 & 1.14 \\
\hline HN3 & $0.50 \pm 0.00 \mathrm{cdef}$ & $0.25 \pm 0.03 \mathrm{bcd}$ & 50.00 & 2.08 \\
\hline HWT2 & $0.25 \pm 0.03 \mathrm{fg}$ & $0.20 \pm 0.06 \mathrm{~cd}$ & 76.67 & 1.21 \\
\hline MZT1 & $0.35 \pm 0.09 \mathrm{defg}$ & $0.10 \pm 0.00 \mathrm{~d}$ & 32.86 & 3.67 \\
\hline HWT1 & $0.20 \pm 0.00 \mathrm{~g}$ & $0.15 \pm 0.03 \mathrm{~cd}$ & 75.00 & 1.33 \\
\hline LT8 & $0.15 \pm 0.03 \mathrm{~g}$ & $0.10 \pm 0.00 \mathrm{~d}$ & 72.22 & 1.70 \\
\hline GLT31 & $0.40 \pm 0.06 \mathrm{defg}$ & $0.30 \pm 0.06 \mathrm{bcd}$ & 73.89 & 1.24 \\
\hline ZT8 & $0.70 \pm 0.06 \mathrm{bc}$ & $0.30 \pm 0.06 \mathrm{bcd}$ & 42.06 & 2.39 \\
\hline ZYT1 & $0.35 \pm 0.03$ defg & $0.25 \pm 0.03 \mathrm{bcd}$ & 73.81 & 1.57 \\
\hline JGX & $0.30 \pm 0.00 \mathrm{efg}$ & $0.15 \pm 0.03 \mathrm{~cd}$ & 50.00 & 1.99 \\
\hline YT30 & $1.05 \pm 0.03 \mathrm{a}$ & $0.60 \pm 0.06 \mathrm{a}$ & 56.93 & 2.04 \\
\hline HZ388 & $0.30 \pm 0.00 \mathrm{efg}$ & $0.20 \pm 0.00 \mathrm{~cd}$ & 66.67 & 0.99 \\
\hline $\mathrm{HC} 11$ & $0.60 \pm 0.00 \mathrm{bcd}$ & $0.20 \pm 0.06 \mathrm{~cd}$ & 33.33 & 3.15 \\
\hline GT18 & $0.40 \pm 0.06 \mathrm{defg}$ & $0.25 \pm 0.03 \mathrm{bcd}$ & 63.06 & 1.57 \\
\hline НТ309 & $0.25 \pm 0.03 \mathrm{fg}$ & $0.10 \pm 0.00 \mathrm{~d}$ & 41.11 & 2.03 \\
\hline F value & - & - & $2.28 *$ & $4.28 * *$ \\
\hline
\end{tabular}

Note. Different lowercases in the same column indicated significant differences at 0.05 level. RTEL, the root tip elongated length.

\subsubsection{Effect on Chlorophyll Content}

Chlorophyll content was determined in the 18 sweet corn varieties' seedlings under Al stress (Figure 1). The relative chlorophyll content in the majority of sweet corn varieties decreased by $0.200-7.233$ with Al treatment. MZT showed the greatest significant decrease in chlorophyll content and the content of chlorophyll content in HC11 and HT309 decreased significantly, as well. On the contrary, the chlorophyll content of HWT2, JGX, and HZ388 increased slightly under $\mathrm{Al}$ treatment, but the difference was non-significant.

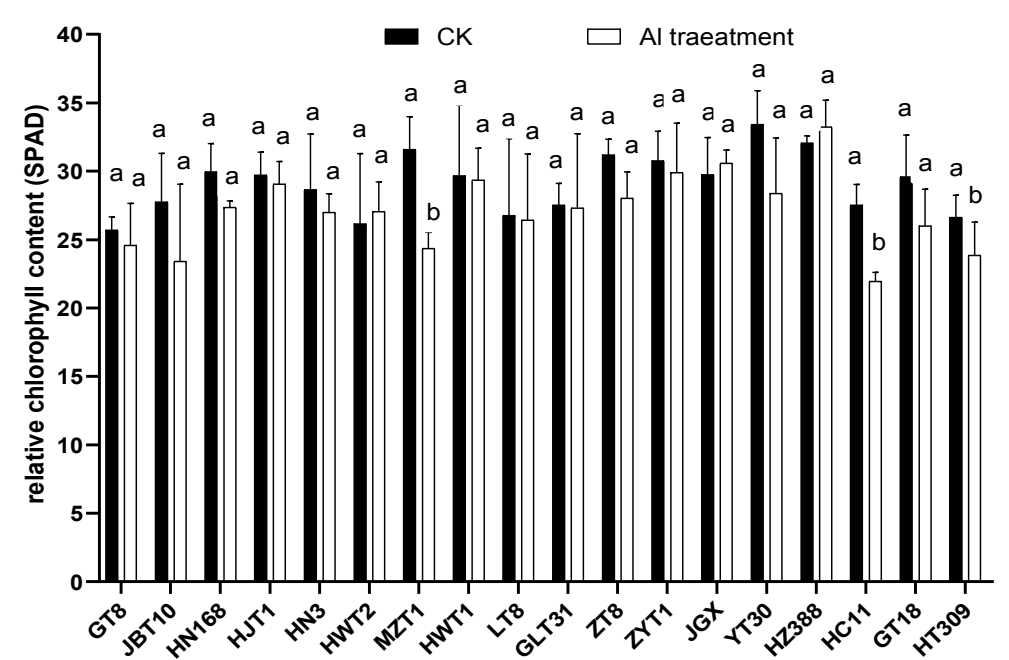

Figure 1. Effect of aluminum treatment on chlorophyll content in seedling of 18 sweet corn varieties

Note. Different lowercases of the same variety indicate significant differences between $0.0 \mathrm{mmol} \mathrm{L}^{-1} \mathrm{AlCl}_{3}(\mathrm{CK})$ and $0.4 \mathrm{mmol} \mathrm{L}^{-1} \mathrm{AlCl}_{3}$ (Al treatment) at 0.05 level. 


\subsubsection{Effects on Plant Height and Fresh Weight}

Plant height and fresh weight under Al treatment were observed in 18 sweet corn varieties' seedlings (Figure 2). Under $0.4 \mathrm{mmol} \mathrm{L}^{-1} \mathrm{AlCl}_{3}$ treatment, the plant height in 15 sweet corn varieties decreased by $5.01 \%$ to $27.16 \%$ in comparison to CK. Among them, the plant height of HN168, HN3, MZT1, ZT8, HC11, and HT309 decreased significantly, while the plant height of HWT2, HWT1, and HZ388 increased by $2.86 \%$ to $3.89 \%$ compared to the $0.0 \mathrm{mmol} \mathrm{L}^{-1} \mathrm{AlCl}_{3}$ treatment group with the non-significant difference (Figure 2A). The seedling fresh weight of 13 sweet corn varieties decreased by $8.30 \%$ to $38.07 \%$ under $0.4 \mathrm{mmol} \mathrm{L}^{-1} \mathrm{AlCl}_{3}$ treatment and variety $\mathrm{HN} 3$, MZT1, GLT31, ZT8, ZYT1, JGX, HZ388, HC11, HT309 showed a significant decline at the p-value level of 0.05. It is interesting to note that the fresh weight of HWT2, LT8, JGX, YT30 and GT18 increased under the Al toxicity treatment and variety JGX and GT18 showed a significant increase (Figure 2B).
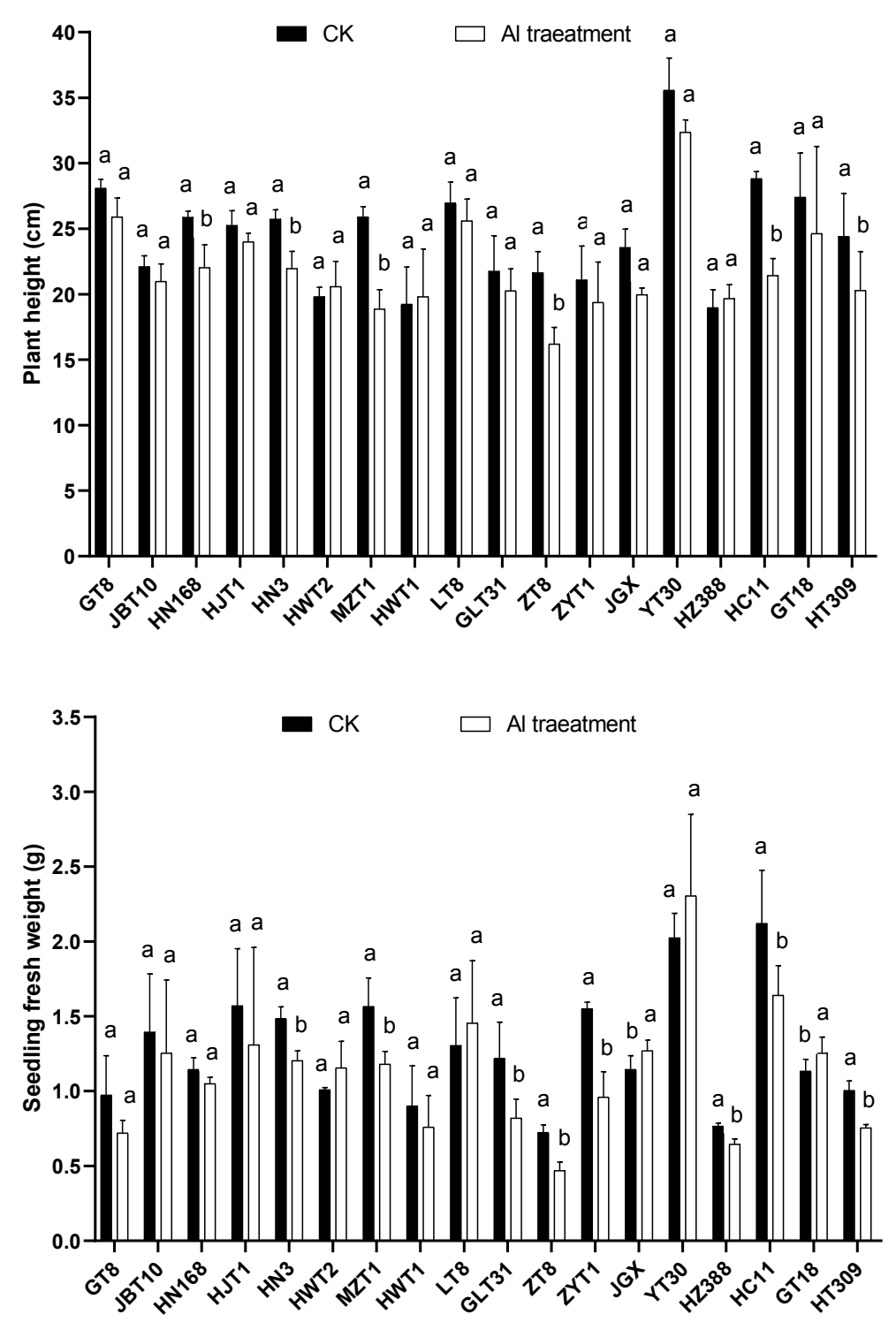

Figure 2. The effect of aluminum treatment on plant height and seedling fresh weight among 18 sweet corn varieties

Note. (A) Effect on plant height under aluminum treatment. (B) Effect on seedling fresh weight under aluminum treatment. 


\subsubsection{Effects on Antioxidative Enzymes Activity}

$\mathrm{Al}$ treatment affected the SOD, POD and CAT activity in 18 sweet corn varieties' seedlings (Figure 3). Under 0.4 mmol L-1 $\mathrm{AlCl}_{3}$ treatment, the SOD activity significantly decreased by $0.930 \mathrm{U} \mathrm{g}^{-1} \mathrm{FW}$ to $56.580 \mathrm{U} \mathrm{g}^{-1} \mathrm{FW}$ in comparison to CK among 18 sweet corn varieties except for HWT2, MZT1 and JGX and variety HWT2 decreased at the non-significant level. In contrast, SOD activity of MZT1 and JGX, increased significantly at the level of 0.05 . POD activity was increased due to $\mathrm{Al}$ treatment in 16 sweet corn varieties, which reached a significant level in variety JBT10, HN168, HN3, WHT2, HWT1, LT8, ZT8, ZYT1, JGX, YT30, HC11, GT18 and HT309. Al treatment resulted in the decrease of POD activity in variety HJT1 and GLT31 with a non-significant level. The effect of Al treatment on CAT activity is not regular. CAT activity decreased in variety GT8, JBT10, HN168, HN3, HWT2, MZT1, ZT8, YT30, HC11 and HT309 after the Al treatment, which reached a significant level of 0.05 . Al treatment led to a significant increase in the variety HJT1, HWT1, LT8, GLT31, ZYT1, JGX, HZ388 and GT18. The maximum addition of CAT activity was HJT1 and HZ388 with 102.725 $\mathrm{U} \mathrm{g}^{-1}$ and $156.295 \mathrm{U} \mathrm{g}^{-1}$, respectively. 

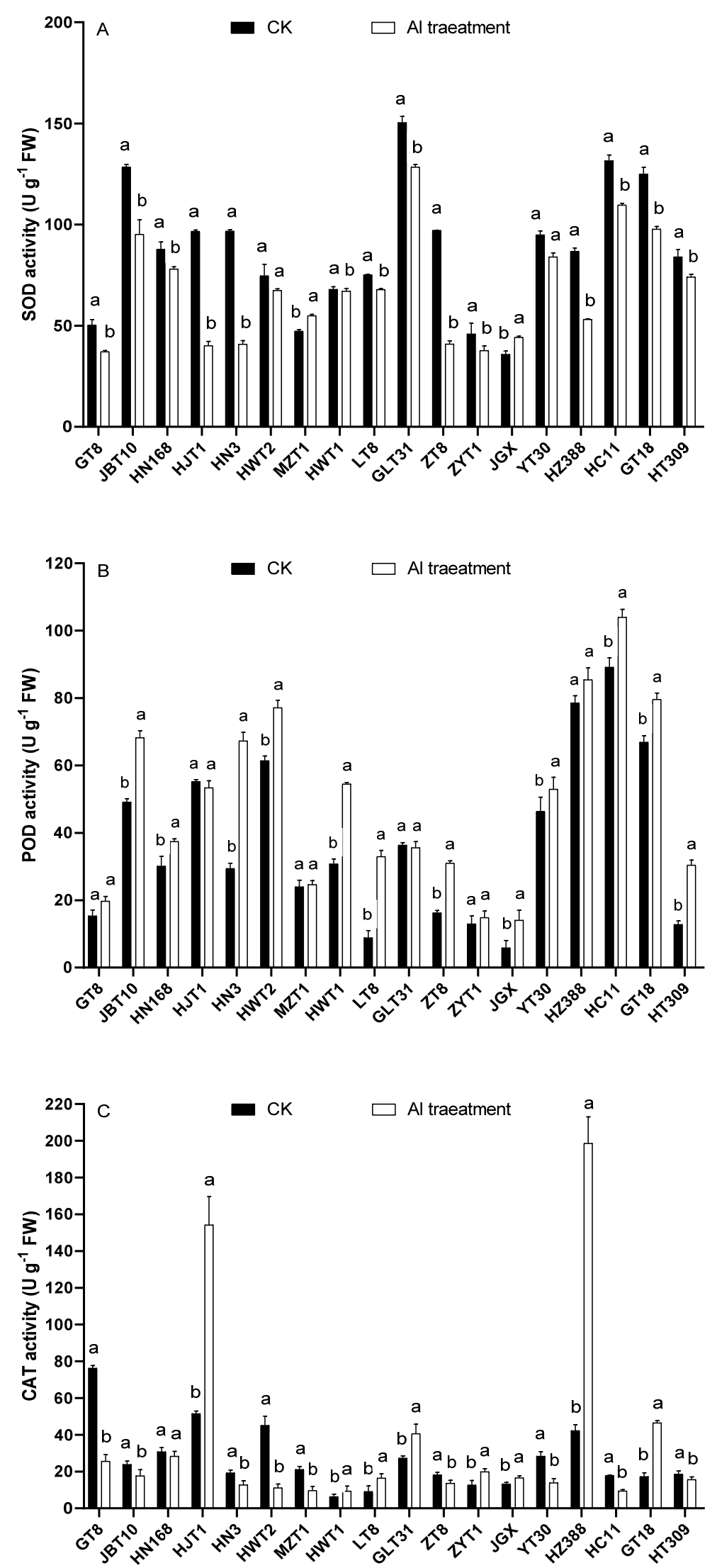

Figure 3. Effect of Al treatment on SOD, POD and CAT activities in 18 sweet corn variety seedlings

Note. (A) Effect on SOD Activity under Aluminum Treatment. (B) Effect on POD Activity under Aluminum Treatment. (C) Effect on CAT Activity under Aluminum Treatment. 


\subsection{Correlation Analysis of Al-Induced Morphological and Physiological Indexes of Sweet Corn Seedlings}

The correlation analysis of morphological and physiological indexes under Al treatment had been performed (Table 3). A few significant correlations had been detected in this study. Al content in root tips was negatively correlated with relative root growth ratio and relative chlorophyll content at a significant level of 0.01 . Of them, the maximum correlation coefficient between $\mathrm{Al}$ content in root tips and relative root growth ratio was -0.86 . $\mathrm{Al}$ content in root tips was negatively correlated with CAT activity at the significant level of 0.05 . There were significant positive correlations between plant height and fresh weight with the correlation coefficient of 0.73 , and relative chlorophyll content was positively correlated with relative root growth ratio and CAT at the significant level of 0.05 .

Table 3. Analysis of correlation about the changes of growth and physiological indexes of sweet corn seedlings under aluminum stress

\begin{tabular}{lllllllll}
\hline Variable & RRG & RCC & PH & SFW & SOD & POD & CAT & ACRT \\
\hline RRG & 1.00 & & & & & & & \\
RCC & $0.59^{*}$ & 1.00 & & & & & & \\
PH & 0.15 & -0.10 & 1.000 & & & & & \\
SFW & -0.06 & -0.20 & $0.73^{* *}$ & 1.00 & & & & \\
SOD & -0.03 & -0.43 & 0.16 & 0.29 & 1.00 & & & \\
POD & 0.09 & -0.13 & 0.10 & 0.27 & 0.42 & 1.00 & & \\
CAT & 0.42 & $0.55^{*}$ & -0.02 & -0.19 & -0.18 & 0.29 & 1.00 & \\
ACRT & $-0.86^{* *}$ & $-0.59^{* *}$ & -0.11 & 0.23 & 0.01 & -0.11 & $-0.50^{*}$ & 1.00 \\
\hline
\end{tabular}

Note. $*$ and ** indicate significant difference at the level of 0.05 and 0.01. RRG, Relative root growth ratio (\%); $\mathrm{RCC}$, the relative chlorophyll content; PH, plant height; SFW, seedling fresh weight; ACRT, aluminum content of root tips.

\subsection{The Principal Component Analysis of Morphological and Physiological Traits under Al Stress}

The principal component analysis of morphological and physiological traits under $\mathrm{Al}$ treatment was performed and the coefficients of these principal components were calculated (Table 4, 5). Four principal components were detected with the cumulative contribution rate of $87.843 \%(>85 \%)$, and the individual contribution rates of $36.424 \%, 25.339 \%, 15.502 \%$, and $10.579 \%$, respectively. Among them, the largest contribution to the Prin 1 was the relative root growth ratio and $\mathrm{Al}$ content of root tip. Plant height and seedling fresh weight contributed the most to the Prin2. The largest contribution to the Prin 3 was SOD activity, and for the Prin 4 was POD activity. Therefore, the main factors affecting on the morphological and physiological traits under Al treatment, were relative root growth ratio, Al content in root tips, plant height, seedling fresh weight, SOD activity and POD activity. The results showed that Prin1 indicated the inhibition to root and the root growth, Prin2 indicated the plant growth, Prin3 and Prin4 indicated the SOD and POD activity, respectively.

Table 4. Eigenvalue, contribution ratio and cumulative contribution rate of main factors analysis

\begin{tabular}{lllllllll}
\hline & Prin1 & Prin2 & Prin3 & Prin4 & Prin5 & Prin6 & Prin7 & Prin8 \\
\hline Eigenvalue & 2.91 & 2.03 & 1.24 & 0.85 & 0.39 & 0.35 & 0.16 & 0.07 \\
Contribution ratio & 36.42 & 25.34 & 15.50 & 10.58 & 4.82 & 4.38 & 2.05 & 0.91 \\
Cumulative contribution rate & 36.42 & 61.76 & 77.26 & 87.84 & 92.66 & 97.04 & 99.09 & 100.00 \\
\hline
\end{tabular}

Note. Prin1-8, Principal component1-8. 
Table 5. Eigenvector of main factors analysis

\begin{tabular}{lllll}
\hline Eigenvector & Prin1 & Prin2 & Prin3 & Prin4 \\
\hline Relative root growth ratio & 0.95 & 0.08 & -0.04 & -0.02 \\
Relative chlorophyll content & 0.42 & -0.08 & -0.25 & -0.09 \\
Plant height & 0.15 & 0.96 & 0.04 & -0.01 \\
Seedling fresh weight & -0.15 & -0.86 & 0.14 & 0.19 \\
SOD activity & 0.01 & 0.12 & -0.95 & 0.22 \\
POD activity & 0.02 & 0.10 & 0.22 & 0.96 \\
CAT activity & -0.27 & -0.05 & -0.10 & 0.19 \\
Al content in root tips & -0.91 & -0.04 & -0.04 & -0.07 \\
\hline
\end{tabular}

Note. Prin1-4, Principal component1-4.

\section{Discussion}

Once Al-induced toxicity stress occurs in acidic soil, plant root elongation is inhibited at first, and then the absorption of water and mineral nutrient elements is disrupted eventually resulting in the decrease of crop quality and yield (Kochian, 1995). The inhibition of root elongation is a common reaction in higher plants in the presence of even low concentration (in micromoles) of $\mathrm{Al}$ for a short period (Collins et al., 2008). For this reason, relative elongation of roots is usually used to measure the degree of $\mathrm{Al}$ toxicity in plants (Collet et al., 2002). Our results showed that the root elongation was noticeably inhibited by $\mathrm{Al}$ treatment, with a significant decrease in the relative root growth ratio after $24 \mathrm{~h}$ of treatment with $0.4 \mathrm{mmol} \mathrm{L}^{-1} \mathrm{AlCl}_{3}$. Among 18 sweet corn varieties, HJT1, HWT2, and HWY1 exhibited higher relative root growth ratio and lower Al content of root tip, while the other varieties including MZT1, HC11, and ZT8 exhibited lower relative root growth ratio and higher Al content of root tip. The results also showed that $\mathrm{Al}$ accumulation in the root tip was negatively correlated with relative root growth ratio, which is consistent with the results reported by Pineros et al. (2005). The first principal component also pointed to the inhibition of root production by aluminum treatment.

Chlorophyll is an important photosynthetic pigment. Its content reflects the intensity of plant photosynthesis to a certain extent and affects the normal plant growth (Golldack et al., 2011). The intracellular ion content in plant leaves increased under Al stress, which decreased the binding affinity between chlorophyll and chloroplast proteins, and promoted decomposition of chlorophyll (Pardo, 2010). Chlorophyll content in leaves represents one of the indexes of $\mathrm{Al}$ tolerance in plants (Chaves et al., 2009). Under aluminum stress the growth of leaves was inhibited, the plant height and the branch number were decreased (Yang et al., 1996). In our study, plant height and fresh weight in most sweet corn varieties were significantly decreased under Al treatment in this study, and the correlation analysis showed a significant positive correlation between plant height and fresh weight. It is consistent with the previous research. On the contrary, Al treatment promoted the plant height of HWT2, HWT1 and HZ388 and it also increased the seedling fresh weight of JGX and GT18. Several studies have shown that low Al concentrations can promote plant growth (Petra \& Proctor, 2000; Ciamporova, 2002). It might be that the critical concentration of aluminum tolerated by these varieties is higher than $0.4 \mathrm{mmol} \mathrm{L}^{-1} \mathrm{AlCl}_{3}$.

Under normal conditions, the production and scavenging of ROS are balanced and not harmful to plant cells (Apel \& Hirt, 2004). In recent years, it has been shown that Al stress can increase the concentration of ROS in pea (Yamamoto et al., 2001), soybean (Cackm \& Horst, 1991), rye (He et al., 2005), and tobacco (Liu et al., 2017). SOD, POD, and CAT protect the plant from excessive accumulation of ROS (Wu et al., 2017). SOD, CAT, and POD can reduce or maintain the concentration of ROS at the low levels, thereby reducing the overall damage to plant cells and tissues (Dunand et al., 2007). In this study, POD activity increased after Al treatment and it confirmed the previous research. Furthermore, SOD activity of the majority of 18 sweet corn varieties was decreased significantly after $\mathrm{Al}$ treatment, which might be a result of limited resistance of these varieties to $\mathrm{Al}$ stress. A significant negative correlation had been detected between the CAT activity and Al content in root tips among all three antioxidases. This study confirmed the significant differences in the antioxidase activities among different sweet corn varieties under Al stress and showed that the response of sweet corn to aluminum stress was a complex trait regulated by multiple genes.

Taken together, four principal components were detected by principal analysis and they indicated the inhibition to root and the root growth, the plant growth, the SOD and POD activity, respectively. HWT2, HWT1 and HZ388 have a higher relative root growth ratio and lower Al content in root tips. The plant height of three varieties increased under Al treatment and the seedling fresh weight of HWT2 increased after Al treatment. 
HWT2 and HWT1 were bred by the same company in Guangzhou they might have a common parent. These three varieties might have a higher tolerance to Al treatment among 18 sweet corn varieties and this will provide material for aluminum stress tolerance breeding.

\section{Acknowledgements}

We thank Dr. Wang Bo for its linguistic assistance during the preparation of this manuscript.

\section{References}

Apel, K., \& Hirt, H. (2004). Reactive oxygen species: metabolism, oxidative stress, and signal transduction. Annu. Rev. Plant Biol., 55, 373-399. https://doi.org/10.1146/annurev.arplant.55.031903.141701

Bojórquez-Quintal, E., Escalante-Magaña, C., Echevarría-Machado, I., \& Martínez-Estévez, M. (2017). Aluminum, a friend or foe of higher plants in acid soils. Frontiers Plant Sci., 8, 1767. https://doi.org/10.3389/fpls.2017.01767

Boscolo, P. R., Menossi, M., \& Jorge, R. A. (2003). Aluminum-induced oxidative stress in maize. Phytochemistry, 62, 181-189. https://doi.org/10.1016/S0031-9422(02)00491-0

Cakmak, I., \& Horst, W. J. (1991). Effect of aluminium on lipid peroxidation, superoxide dismutase, catalase, and peroxidase activities in root tips of soybean (Glycine max). Physiol. Plant, 83, 463-468. https://doi.org/ 10.1111/j.1399-3054.1991.tb00121.x

Chaves, M. M., Flexas, J., \& Pinheiro, C. (2009). Photosynthesis under drought and salt stress: Regulation mechanisms from whole plant to cell. Ann. Bot., 103, 551-560. https://doi.org/10.1093/aob/mcn125

Ciamporova, M. (2002). Morphological and structural response of plant roots to aluminium at organ, tissue and cellular levels. Biol. Plant, 45, 161-171. https://doi.org/10.1023/A:1015159601881

Collet, L., Leon, C., Kollmeier, M., Schmohl, N., \& Horst, W. J. (2002). Assessment of aluminum sensitivity of maize cultivars using roots of intact plants and excised root tips. J. Plant Nutr. Soil Sci., 165, 357-365. https://doi.org/10.1002/1522-2624(200206)165:3\%3C357::AID-JPLN357\%3E3.0.CO,2-V

Collins, N. C., Shirley, N. J., Saeed, M., Pallotta, M., \& Gustafson, J. P. (2008). An ALMT1 gene cluster controlling aluminum tolerance at the Alt4 locus of rye (Secale cereale L.). Genetics, 179, 669-682. https://doi.org/10.1534/genetics.107.083451

Dietz, K. J., Mittler, R., \& Noctor, G. (2016). Recent progress in understanding the role of reactive oxygen species in plant cell signaling. Plant Physiol., 171, 1535-1539. https://doi.org/10.1104/pp.16.00938

Foy, C. D., Chaney, R. L., \& White, M. C. (1978). The physiology of metal toxicity in plants. Annu. Rev. Plant Physiol., 29, 511-566. https://doi.org/10.1146/annurev.pp.29.060178.002455

Golldack, D., Lüking, I., \& Yang, O. (2011). Plant tolerance to drought and salinity: stress regulating transcription factors and their functional significance in the cellular transcriptional network. Plant Cell Rep., 30, 1383-1391. https://doi.org/10.1007/s00299-011-1068-0

He, H., He, L., Li, X., \& Gu, M. (2005). Effects of Aluminum Stress on Reactive Oxygen Generation, Lipid Peroxidation and Antioxidant Enzyme Activity in Rye Seedling. Acta. Tritical Crops, 6.

Huang, B. Q., Bai, J. H., \& Xue, X. Q. (2001). Advances in studies on aluminum toxicity and tolerance in plants. Chinese Bulletin of Botany, 18, 385-395.

Huang, W., Yang, X., Yao, S., LwinOo, T., He, H., Wang, A., \& He, L. (2014). Reactive oxygen species burst induced by aluminum stress triggers mitochondria-dependent programmed cell death in peanut root tip cells. Plant Physiol. Biochem., 82, 76-84. https://doi.org/10.1016/j.plaphy.2014.03.037

Kochian, L. V. (1995). Cellular mechanisms of Al toxicity and resistance in plants. Annu. Rev. Plant Physiol., Mol. Biol., 46, 237-260. https://doi.org/10.1146/annurev.pp.46.060195.001321

Kochian, L. V. (1995). Cellular mechanisms of aluminum toxicity and resistance in plants. Annu. Rev. Plant Biol., 46, 237-260. https://doi.org/10.1146/annurev.pp.46.060195.001321

Kollmeier, M., Felle, H. H., \& Horst, W. J. (2000). Genotypic difference in Al resistance of maize are expressed in the distal part of the transition zone.Is reduced basipetal in the distal aux-in flow involved in inhibition of root elongation by Al? Plant Physiol., 122, 945-956. https://doi.org/10.1104/pp.122.3.945 
Liu, Q., Hu, C., Liu, Z. W., \& Song, Y. S. (2017). Effects of aluminum stress on light energy utilization, photoprotective systems and reactive oxygen metabolism in leaves of tobacco seeedlings. Acta. Agric. Boreali-Sinica, 32, 118-124.

Macdonald, T. L., \& Martin, R. B. (1988). Aluminum ion in biological systems. Trends Biochem. Sci., 13, 15-19. https://doi.org/10.1016/0968-0004(88)90012-6

Matsumoto, H. (2000). Cell of biology of aluminium toxicity and tolerance in higher plants. Int. Rev. Cytol., 200, 1-46. https://doi.org/10.1016/S0074-7696(00)00001-2.

Pardo, J. M. (2010). Biotechnology of water and salinity stress tolerance. Curr. Opin. Biotechnol., 21, $185-196$. https://doi.org/10.1016/j.copbio.2010.02.005

Piñeros, M. A., \& Kochian, L. V. (2001). A patch-clamp study on the physiology of aluminum toxicity and aluminum tolerance in maize: Identification and characterization of $\mathrm{Al}^{3+}$-induced anion channels. Plant Physiol., 125, 292-305. https://doi.org/10.1104/pp.125.1.292

Piñeros, M. A., Shaff, J. E., Manslank, H. S., Alves, V. M. C., \& Kochian, L. V. (2005). Aluminum resistance in maize cannot be solely explained by root organic acid exudation: A comparative physiological study. Plant Physiol., 137, 231-241. https://doi.org/10.1104/pp.104.047357

Rengel, Z. (1992). Disturbance of cell $\mathrm{Ca}^{2+}$ homeostasis as primary trigger of toxicity syndrome. Plant Cell Enviro., 15, 931-938. https://doi.org/10.1111/j.1365-3040.1992.tb01025.x

Ryan, P. R., \& Delhaize, E. (2010). The convergent evolution of aluminum resistance in plants exploits a convenient currency. Funct. Plant Biol., 37, 275-284. https://doi.org/10.1071/FP09261

Ulrich, B., \& Panbrath, J. (1983). Effects of Accumulation Air Pollutants in Forest Ecosystem (Vol. 83, p. 331). Dordrecht, Holland: D. Reided Publishing Company. https://doi.org/10.1007/978-94-009-6983-4

Wise, R. R., \& Naylor, A. W. (1987). Chilling-enhanced photooxidation: Evidence for the role of singlet oxygen and superoxide in the breakdown of pigments and endogenous antioxidants. Plant Physiol., 83, $278-282$. https://doi.org/10.1104/pp.83.2.278

Wu, Z., Liu, S., Zhao, J., Wang, F., Du, Y., Zou, S., \& Huang, Y. (2017). Comparative responses to silicon and selenium in relation to antioxidant enzyme system and the glutathione-ascorbate cycle in flowering Chinese cabbage (Brassica campestris L. ssp. chinensis var. utilis) under cadmium stress. Environ. Exp. Bot., 133, 1-11. https://doi.org/10.1016/j.envexpbot.2016.09.005

Yamamoto, Y., Kobayashi, Y., \& Matsumoto, H. (2001). Lipid peroxidation is an early symptom triggered by aluminum, but not the primary cause of elongation inhibition in pea roots. Plant Physiol., 125, 199-208. https://doi.org/10.1104/pp.125.1.199

Yamamoto, Y., Kobayashi, Y., Devi, S. R., Rikiishi, S., \& Matsumoto, H. (2002). Aluminum toxicity is associated with mitochondrial dysfunction and the production of reactive oxygen species in plant cells. Plant Physiol., 128, 63-7. https://doi.org/10.1104/pp.010417

Yang, Y., Guo, Z. H., Geng, M. J., Wang, W., Ning, D. W., \& Zhao, Z. Q. (2010). Active oxygen metabolism differences and $\mathrm{Al}$ tolerance of different Al-tolerant wheat under aluminum stress. Ecol. Environ. Sci., 19, 177-182.

Yang, Z., Feng, X., \& Mou, J. (1996). Effect of aluminium on the growth and some physiological characters of Eucalyptus seedlings. Guangxi Sciences, 3, 30-33. https://doi.org/10.1371/journal.pone.0130963

Zhao, H., He, L., \& Zhang, A. (2008). Advance in the study of effects of aluminum stress on plant photosynthesis and its mechanism. Journal-Huazhong Agricultural University, 27, 155.

Zhou, L., Jie G., Zhang Z., Huang F., Gao S., \& Zhang S. (2014). Responses of two maize inbred lines of different aluminium tolerance to Alinduced oxidative stress. Chin. J. Appl. Environ. Biol., 20, 669-674.

\section{Copyrights}

Copyright for this article is retained by the author(s), with first publication rights granted to the journal.

This is an open-access article distributed under the terms and conditions of the Creative Commons Attribution license (http://creativecommons.org/licenses/by/4.0/). 